\title{
Editorial
}

\section{Sustainable Water Systems}

\section{Miklas Scholz}

Civil Engineering Research Centre, School of Computing, Science and Engineering, The University of Salford, Newton Building, Salford M5 4WT, England, UK; E-Mail: m.scholz@salford.ac.uk; Tel.: +44-161-2955921; Fax: +44-161-2955575

Received: 21 January 2013; in revised form: 1 February 2013 / Accepted: 1 February 2013 / Published: 6 February 2013

\begin{abstract}
Sustainable water systems often comprise complex combinations of traditional and new system components that mimic natural processes. These green systems aim to protect public health and safety, and restore natural and human landscapes. Green infrastructure elements such as most sustainable drainage systems trap storm water but may contaminate groundwater. There is a need to summarize recent trends in sustainable water systems management in a focused document. The aim of this special issue is therefore to disseminate and share scientific findings on novel sustainable water systems addressing recent problems and opportunities. This special issue focuses on the following key topics: climate change adaptation and vulnerability assessment of water resources systems; holistic water management; carbon credits; potable water savings; sustainable water technologies; nutrient management; holistic storm water reuse; water and wastewater infrastructure planning; ecological status of watercourses defined by the Water Framework Directive. The combined knowledge output advances the understanding of sustainable water, wastewater and storm water systems in the developed and developing world. The research highlights the need for integrated decision-support frameworks addressing the impact of climate change on local and national water resources management strategies involving all relevant stakeholders at all levels.
\end{abstract}

Keywords: climate change adaptation; water resources system; water management; carbon credits; potable water savings; sustainable water technology; nutrient management; storm water reuse; infrastructure planning; watercourse ecology 


\section{Introduction}

Most sustainable water systems comprise novel combinations of traditional and new system components that mimic and work with nature [1-11]. These systems protect public health and safety, and restore natural and human landscapes [11]. Large-scale systems in particular help to restore and preserve vegetation and wildlife, and minimize climate change and global warming [1-4,10]. Green cities focus on the restoration of natural cycles of water infiltration and evaporation through localized treatment and groundwater recharge via sustainable drainage systems, trees, parks, roof gardens and stream restoration [11]. Smart growth promoting patterns of neighborhood development interconnect nature and the built environment, preserving open space and respecting natural drainage flows $[8,10]$.

Green infrastructure such as most sustainable drainage systems (or best management practices) trap storm water and sustain plants such as trees $[8,10,11]$. Particularly trees restore beauty and improve the air quality in cities, moderate energy flows and provide potential food sources. Onsite and neighborhood treatment via small-scale technologies such as wetlands mimicking natural membranes and filters utilizing soils and smart localized controls is encouraged for small communities [11]. Onsite reuse include closed-loop water systems in residential and commercial buildings, where storm water and wastewater are treated and reused for landscape irrigation, toilet flushing and cooling, and where minimal waste leaves the site [4,10].

The aim of this special issue is to disseminate and share recent global findings on novel sustainable water systems addressing problems and opportunities scientifically, complementing a recent review paper on European advances in sustainable multifunctional land and urban management [10] and a recent British textbook on wetlands, sustainable technology and green infrastructure [11]. Original research papers were selected by a rigorous peer review procedure with the aim of rapid and wide dissemination of research results, developments and applications in the wider area of sustainable water systems.

\section{Contributions}

Selected paper contributions to this special issue are highlighted in this section. Two papers had a clear climate change focus [1,2]. Gain et al. [1] provided a generalized framework associated with a feasibility study located in Bangladesh. The paper focuses on climate change adaptation and vulnerability assessments of water resources systems. The proposed framework is particularly relevant for vulnerability assessments of water systems in developing countries. Furthermore, Bloetscher [2] discussed water management problems due to climate change. Moreover, the paper focuses on protecting communities, infrastructure, economies and ecosystem service assets. Policy makers can use the project findings to assess the likely policy and infrastructure needs for different localities.

The need for water savings due to climate change was an important issue for two further contributions [3,4]. Shimizu et al. [3] promoted the creation of carbon credits by saving water. The paper also highlights that carbon dioxide emissions can be significantly reduced through widespread use of water-saving fixtures. Furthermore, potable water savings by using rainwater for non-potable uses in houses were discussed by Souza and Ghisi [4]. Findings show that variables such as catchment 
area, number of residents, potable and rainwater demands, and rainfall influence the sizing of the tank for rainwater storage.

Nanninga et al. [5] discussed sustainable water technologies for peri-urban areas of Mexico City. The study assesses the balancing of urbanization and environmental conservation. The results show that decentralized technologies deliver adequate water supply, sanitation, solid waste and resource recovery services.

Two original papers were concerned with nutrient management in very different climates. Grönlund [6] presents a study on the recovery of two polluted sub-arctic lakes. The paper is mainly discussing the nutrient management of semi-pristine environments. Findings indicate the need to keep phosphorus levels low to allow for sufficient lake oxygenation. Additionally, the ecological status of watercourses such as rivers and streams in Saxony (Germany) has been assessed by Spänhoff et al. [7]. The evaluation was based on the guidance provided by the Water Framework Directive [12], talked about previously by the scientific community $[7,10,11]$. The prospects of water quality improvement are discussed, because the water quality status was inadequate for the absolute majority of watercourses due to high nutrient input.

The final two papers highlighted the growing importance of local stakeholder engagement. Recent problems affecting community attitudes and intended behaviors in storm water reuse are being discussed by Wu et al. [8]. A case study located in Salisbury (Australia) is used to illustrate key issues. Results highlight the importance of early community engagement when introducing best management practices. Moreover, Scott et al. [9] thrashes out scenario planning to address critical uncertainties for robust and resilient water and wastewater infrastructures under conditions of water scarcity and rapid development. Scenario planning is essential for bringing stakeholders into agreement over highly complex problems, supporting the outcomes by $\mathrm{Wu}$ et al. [8].

\section{Conclusions}

This special issue is timely and novel, because it informs the sustainable water systems community about the latest developments in research and practice. Recent research indicates the need for integrated vulnerability assessment, water resources quality and quantity, and decentralized technology decision-support frameworks addressing the impact of climate change on local, regional and national water resources management strategies involving stakeholders at all levels.

\section{Acknowledgments}

The editor thanks the scientific community for offering a wide range of valuable papers and the publisher MDPI for allocating resources towards this special issue.

\section{References}

1. Gain, A.K.; Giupponi, C.; Renaud, F.G. Climate change adaptation and vulnerability assessment of water resources systems in developing countries: A generalized framework and a feasibility study in Bangladesh. Water 2012, 4, 345-366. 
2. Bloetscher, F. Protecting people, infrastructure, economies, and ecosystem assets: Water management in the face of climate change. Water 2012, 4, 367-388.

3. Shimizu, Y.; Toyosada, K.; Yoshitaka, M.; Sakaue, K. Creation of carbon credits by water saving. Water 2012, 4, 533-544.

4. Souza, E.L.; Ghisi, E. Potable water savings by using rainwater for non-potable uses in houses. Water 2012, 4, 607-628.

5. Nanninga, T.A.; Bisschops, I.; López, E.; Martínez-Ruiz, J.L.; Murillo, D.; Essl, L.; Stark1, M. Discussion on sustainable water technologies for peri-urban areas of Mexico City: balancing urbanization and environmental conservation. Water 2012, 4, 739-758.

6. Grönlund, E. The recovery of two polluted subarctic lakes-Towards nutrient management or a pristine state? Water 2012, 4, 793-814.

7. Spänhoff, B.; Dimmer, R.; Friese, H.; Harnapp, S.; Herbst, F.; Jenemann, K.; Mickel, A.; Rohde, S.; Schönherr, M.; Ziegler, K.; Kuhn, K.; Müller, U. Ecological status of rivers and streams in Saxony (Germany) according to the Water Framework Directive and prospects of improvement. Water 2012, 4, 887-904.

8. Wu, Z.; McKay, J.; Keremane, G. Issues affecting community attitudes and intended behaviours in stormwater reuse: A case study of Salisbury, South Australia. Water 2012, 4, 835-847.

9. Scott, C.A.; Bailey, C.J.; Marra, R.P.; Woods, G.J.; Ormerod, K.J.; Lansey, K. Scenario planning to address critical uncertainties for robust and resilient water-wastewater infrastructures under conditions of water scarcity and rapid development. Water 2012, 4, 848-868.

10. Scholz, M.; Hedmark, Å.; Hartley, W. Recent advances in sustainable multifunctional land and urban management in Europe: A review. J. Environ. Plan. Manag. 2012, 55, 833-854.

11. Scholz, M. Series: Green Energy and Technology. In Wetland Systems-Storm Water Management Control; Springer Verlag: Berlin, Germany, 2010.

12. European Union. Directive 2000/60/EC of the European Parliament and of the Council Establishing a Framework for the Community Action in the Field of Water Policy. Available online: http://eur-lex.europa.eu/LexUriServ/LexUriServ.do?uri=CELEX:32000L0060:EN:NOT (accessed on 15 January 2013).

(C) 2013 by the authors; licensee MDPI, Basel, Switzerland. This article is an open access article distributed under the terms and conditions of the Creative Commons Attribution license (http://creativecommons.org/licenses/by/3.0/). 